\title{
20. EVIDENCE OF A LOW-VELOCITY LAYER BENEATH THE ACCRETIONARY PRISM OF THE NANKAI TROUGH: INFERENCES FROM A SYNTHETIC SONIC LOG1
}

\author{
Yutaka Aoki, Japex Geoscience Institute, Inc. \\ Hajimu Kinoshita, Faculty of Science, Chiba University \\ and \\ Hideo Kagami, Ocean Research Institute, University of Tokyo ${ }^{2}$
}

\begin{abstract}
In the Nankai Trough subduction zone, a well-defined decollement characterizes the structure of the accretionary prism. Over the decollement are highly thrusted, accreted trench-wedge turbidites, whereas there are apparently stratified pelagic sediments below. A synthetic sonic log profile obtained from multichannel seismic data from Site 583 showed that the apparently stratified layer has a lower seismic velocity than the overlying accreted sediments. This inversion strongly suggests that the pelagic layer is overpressurized because interstitial water cannot be released through the sedimentary overburden. When the accretion of trench-wedge turbidites proceeds, major thrust faults extending to the decollement are generated and the overpressurized pore water is able to escape to the seafloor through the faults. As a result, the thrust fault plane yields reflections with reversed polarity and the pelagic layer often has normal velocity distribution beyond the major thrust zone.
\end{abstract}

\section{INTRODUCTION}

Seismic profiles after proper normal-moveout (NMO) correction and migration are deemed an ensemble of zero offset traces without any diffraction waves. In other words, the seismic wave after NMO correction is supposed to have a normal incident raypath to the reflector. Because the reflection coefficient for a normal incident seismic wave is described as a function of acoustic impedances of both sides of the reflector, it is possible to calculate acoustic impedances by iteration from a reflection coefficient series or equivalent seismic traces (Lavergne and Willm, 1977; Lindseth, 1976; 1979). This process is the converse of synthetic seismogram derivation.

Seismic profiles, however, lack important information such as absolute reflection strength and general trend of acoustic impedance increase toward depth or time. Calibration of these data using well logging data is of critical importance in obtaining reliable acoustic impedance or velocity function.

During Leg 87, two wells were logged by Schlumberger Singapore, but the sonic log was run at Hole 583F only. Thus, the velocity profile around that well only will be discussed in this paper.

\section{SEISMIC VELOCITY AND PROFILE}

Seismic study of the Nankai Trough was carried out by JAPEX before Leg 87, and profiles were made available (Nasu et al., 1982). Nasu and others (1982) obtained stacking velocities that showed systematic changes from the trench to the inner trench slope and these values are

\footnotetext{
${ }^{1}$ Kagami, H., Karig, D. E., Coulbourn, w. T., et al., Init. Repts. DSDP, 87: Washington (U.S. Govt. Printing Office)

2 Addresses: (Aoki) Japex Geosciences Institute, Inc., Akasaka Twin Tower, 2-17-22, Akasaka, Tokyo 107, Japan; (Kinoshita) Faculty of Science, Chiba University, Chiba, Japan; (Kagami) Ocean Research Institute, University of Tokyo, Tokyo, Japan.
}

quite reliable especially at the lower trench slope. One possible ambiguity is velocity errors caused by diffractions and dipping events. Stacking velocities determined before the stacking and migration process tend to give higher values because of diffracted waves and dipping events. However, these effects are negligible for this deep, landward, trench-slope setting. This is evident from the well-processed profile in which $100 \%$ of stacking velocities are used for migration (Fig. 1).

In contrast to stacking velocities, interval velocities derived from stacking velocity or root mean square (RMS) velocity using Dix's formula (1955) are sometimes associated with considerable errors when the time interval of the layer is very small. Therefore, velocity reanalysis was carried out using multiple common-depth-point (CDP) traces of Line N55-3-1, on which Sites 582 and 583 are located. The results are nearly the same as conventionally determined interval velocities, and the final velocity structure near Site 583 is shown in Figure 1. The decollement layer or the apparently stratified layer beneath the accreted trench-wedge turbidite shows a velocity inversion below the toe of the accretionary prism.

Taking the energy source signature into consideration, the sign of the reflection coefficient is estimated from the seismic profile near Site 583. In Figure 2, a signature on the upper right is the basic wavelet used for the current seismic study. It includes all variables that act on the seismic profile; sea surface reflections at the shot point and receiver point, response of recording system, deconvolution effect, and filtering effect. A characteristic feature of the wavelet is zerophase-like signature with small side robes. To more conveniently identify reflection polarity, the seismic profile shown in Figure 2 shows a reversed polarity compared to the standard profile (Fig. 1, Nasu et al., 1982). The polarity of the basic wavelet is also reversed. A boundary with a positive reflection coefficient yields a small black peak followed by a 

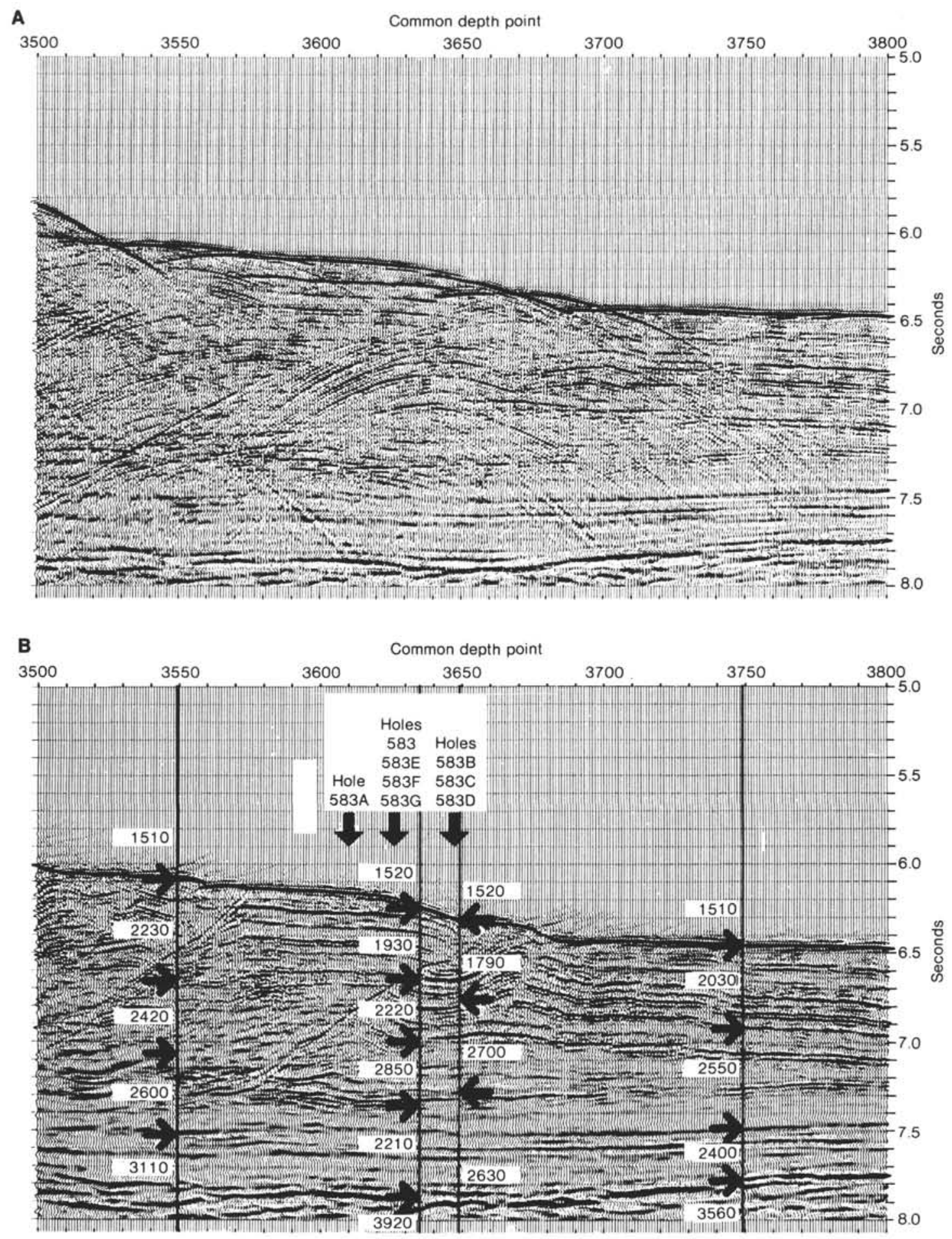

Figure 1. Normal polarity plots of unmigrated (A) and migrated (B) seismic profiles of N55-3-1. Seismic interval velocities $(\mathrm{m} / \mathrm{s})$, determined before drilling, are shown on the migrated section (B).

major negative trough as is clearly indicated by seafloor reflection. In contrast to positive seafloor reflection, the major thrust Faults A and B have negative reflection coefficients showing acoustic impedance decrease or velocity inversion at the faults. Similarly, it is inferred that velocity decreases below the decollement. The best example is around CDP 3700 at $7.53 \mathrm{~s}$.

\section{SYNTHETIC SEISMOGRAM AND SYNTHETIC SONIC LOG}

In order to correlate the seismic profile with well logging data, a synthetic seismogram was generated using full-wave sonic data and formation density. Although conventional sonic data were logged at Hole 583F, the 


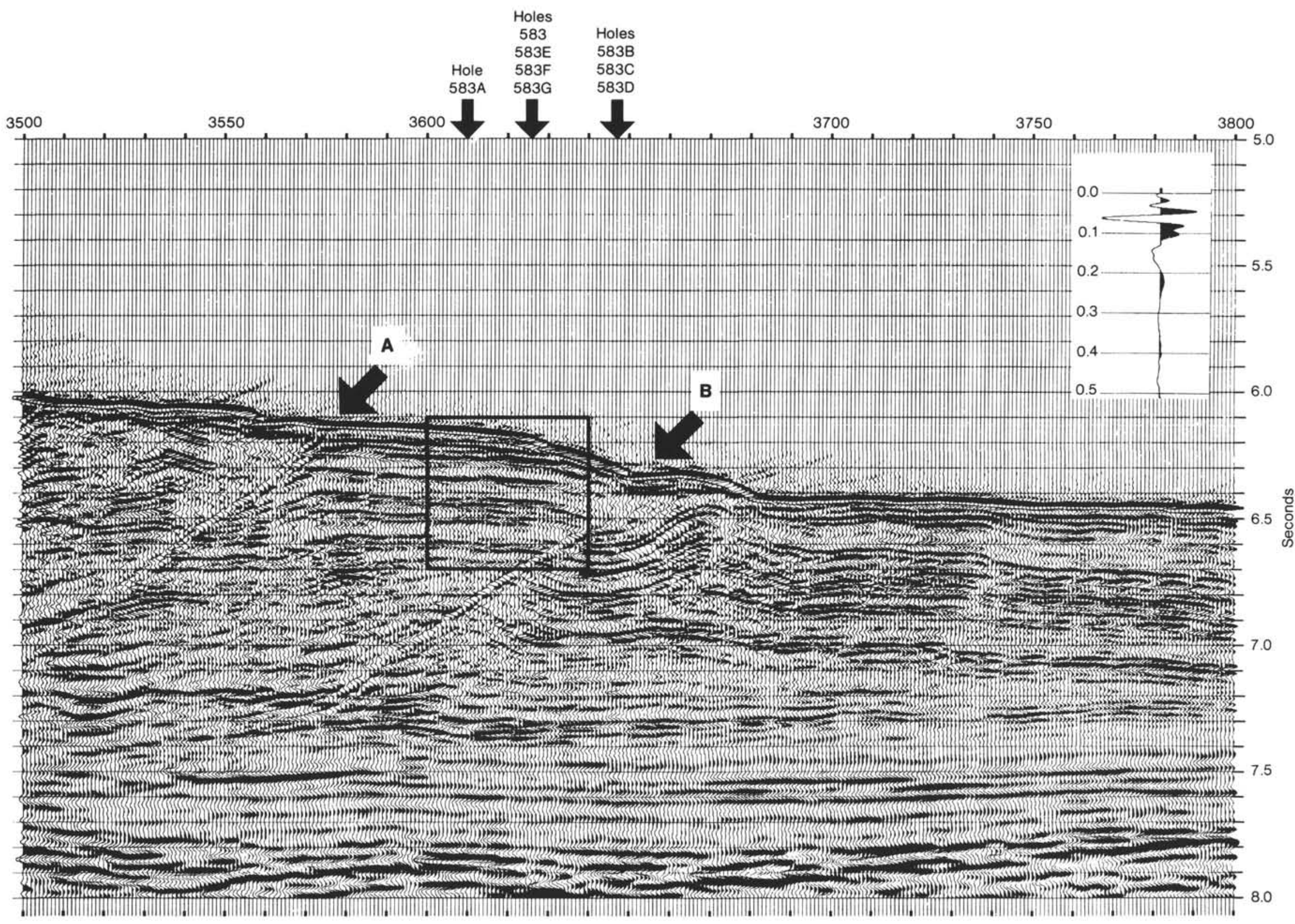

Figure 2. Reversed polarity profile of N55-3-1. A signature on the upper right corner shows the basic wavelet used for the current seismic study (see text). Major thrust faults (indicated by arrows A and B) show negative reflection coefficients. 
data are not reliable because of poor hole conditions. Consequently, the full-wave sonic record is converted to its instantaneous phase profile to get the first arrival time (Fig. 3). The instantaneous phase profile generally provides a clear first break even when the amplitude of the first arrival is very weak. In Figure 3, the same fullwave sonic data, or the "wave form 2" of Schlumberger annotation, is displayed using different expressions. One is the amplitude display with wiggle plus variable area mode, and the other is an instantaneous phase display with color coding (black and white on Fig. 3). The first arrival around $1 \mathrm{~ms}$ can hardly be seen on the amplitude profile but is clearly shown on the phase profile.

In order to get velocity information, two combinations of full-wave sonic data are available from Hole $583 \mathrm{~F}$ with sensor distance groups of 8-10 and $10-12 \mathrm{ft}$. Velocities derived from these data will be called "short full-wave sonic velocity" and "long full-wave sonic velocity", respectively. Short full-wave sonic and long fullwave sonic data have similar $p$-wave velocity curves (Fig. 4), but the differences between the two sometimes exceed $1500 \mathrm{~m} / \mathrm{s}$. A crossplot of the two velocities for 1032 data points reveals a long full-wave sonic average value of $1803 \mathrm{~m} / \mathrm{s}$ between the measured range and a short full-wave sonic value of $1787 \mathrm{~m} / \mathrm{s}$ (Fig. 5). Because this disparity may be caused by a difference in penetration depth from the hole wall and because deeper penetration may reflect the formation velocity more correctly, it was decided to use the long full-wave sonic data for synthetic seismogram derivation.

Velocities from full-wave sonic data were then multiplied by the formation density to get the acoustic impedance, and a reflection coefficient series was generated from that value. Depth-to-time conversion of acoustic impedance was carried out using the depth-time relation curve obtained from both the long full-wave sonic data and the seismic velocity. Because no well shooting data were available from Site 583, the absolute time zero of the synthetic seismogram could not be decided. Finally, the reflection coefficient series in the time domain was convolved with a Ricker wavelet with $30 \mathrm{~Hz}$ central frequency.

The best correlation of the synthetic seismogram with the migrated seismic profile is around CDP 3620 , although the location of Hole $583 \mathrm{~F}$ is officially announced at CDP 3626 (Fig. 6). The discrepancy may be caused partly by the differing navigation systems of the seismic vessel and the drilling vessel and partly by a perpendicular offset of the drilling location.

It is assumed that the synthetic seismogram generated from the logging data between 100 to $257 \mathrm{~m}$ can be correlated with the seismic trace of CDP 3620 between 6.30 and $6.47 \mathrm{~s}$ on the profile. Using the acoustic impedance data or the product of the velocity and the density from the hole, we calibrated the acoustic impedance derived from the seismic profile in the following manner. It is well known that the integrated amplitude of the seismic trace from the surface to a given depth is proportional to the logarithm of acoustic impedance of that depth, provided that the profile is properly processed. Therefore, the integrated data of seismic trace were first scaled, then acoustic impedance values derived from these data were rescaled using the known acoustic impedance from the hole.

In order to derive a velocity function instead of acoustic impedance, the relationship between the two data were displayed (Fig. 7). It is evident from Figure 7 that acoustic impedance can be expressed as a linear function of velocity but that the data are distributed along two lines, a product of the bimodal frequency distribution of the formation density (Fig. 8). This bimodality probably depends on lithology; the higher density group corresponds to the sandy part, whereas the lower density group corresponds to the shaley part. This relationship is also inferred from a crossplot between the formation-density and natural gamma-ray data (Fig. 9).

Alternatively, a density as low as $1.2 \mathrm{~g} / \mathrm{cm}^{3}$ is attributable to contamination by drilling mud. Indeed, formation density has no positive relationship with velocity at Site 583. In order to exclude this ambiguity, it was assumed that the higher density group represents the bulk density $(\rho)$ along the hole according to the equation: $V$ $=0.400 \rho V+334.3$, (Fig. 7) where $V$ indicates velocity. Using this equation, we derived the velocity distribution from the acoustic impedance. Because the seismic trace contains no low-frequency component or normal trend of velocity increase, velocity data obtained in this way may be considered as a high-frequency component of velocity. Therefore, the high-frequency velocity component was combined with velocity data obtained from the CDP traces to give a final result. Thus, Figure 10 shows a gray-scaled velocity profile around Site 583 . To enhance velocity inversion, the zone with $2200-2400 \mathrm{~m} / \mathrm{s}$ $p$-wave velocity is indicated by the lightest gray level. (The frontispiece to this volume is a color-coded version of Fig. 10.) In addition, Figure 10 and the frontispiece (this volume) clearly show that the apparently stratified layer below the well-developed decollement has a lower velocity than the overlying deformed trench-wedge turbidites and that the velocity of the low-velocity layer increases landward.

\section{DISCUSSION}

The logging data obtained at Hole 583F have a very large dispersion within a short logged interval, 100 to $257 \mathrm{~m}$ sub-bottom. For example long full-wave sonic velocity values range from 1290 to $2650 \mathrm{~m} / \mathrm{s}$ and the formation density histogram shows a bimodal distribution ranging from 1.11 to $2.44 \mathrm{~m} / \mathrm{s}$. Both data contain abnormally low values. Furthermore, the logging data are characterized by a poor correlation between sonic velocity and density. Regardless of the type of full-wave sonic velocity (long or short), full-wave sonic data are apparently not related to the formation density. Even a correlation between the two full-wave sonic velocities is not sufficient if compared to industrial oil wells.

A major cause of this lack of correspondence is probably due to poor hole conditions, as indicated by the low core recovery ratio. Nevertheless, general velocity information obtained from the log data shows good agreement with the seismic data. The synthetic seismogram generated from log data correlates well with the seismic 


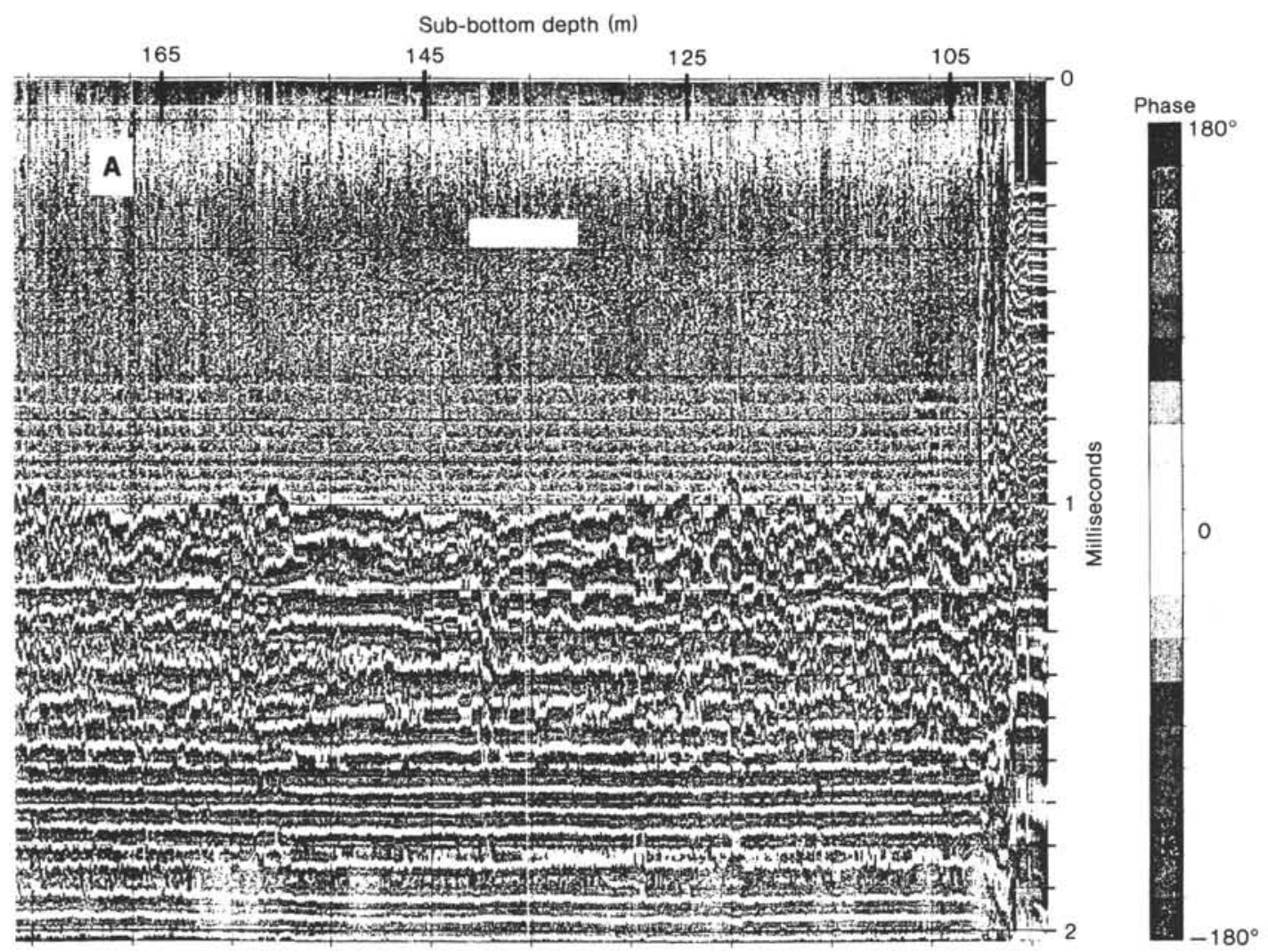

Sub-bottom depth $(\mathrm{m})$

125

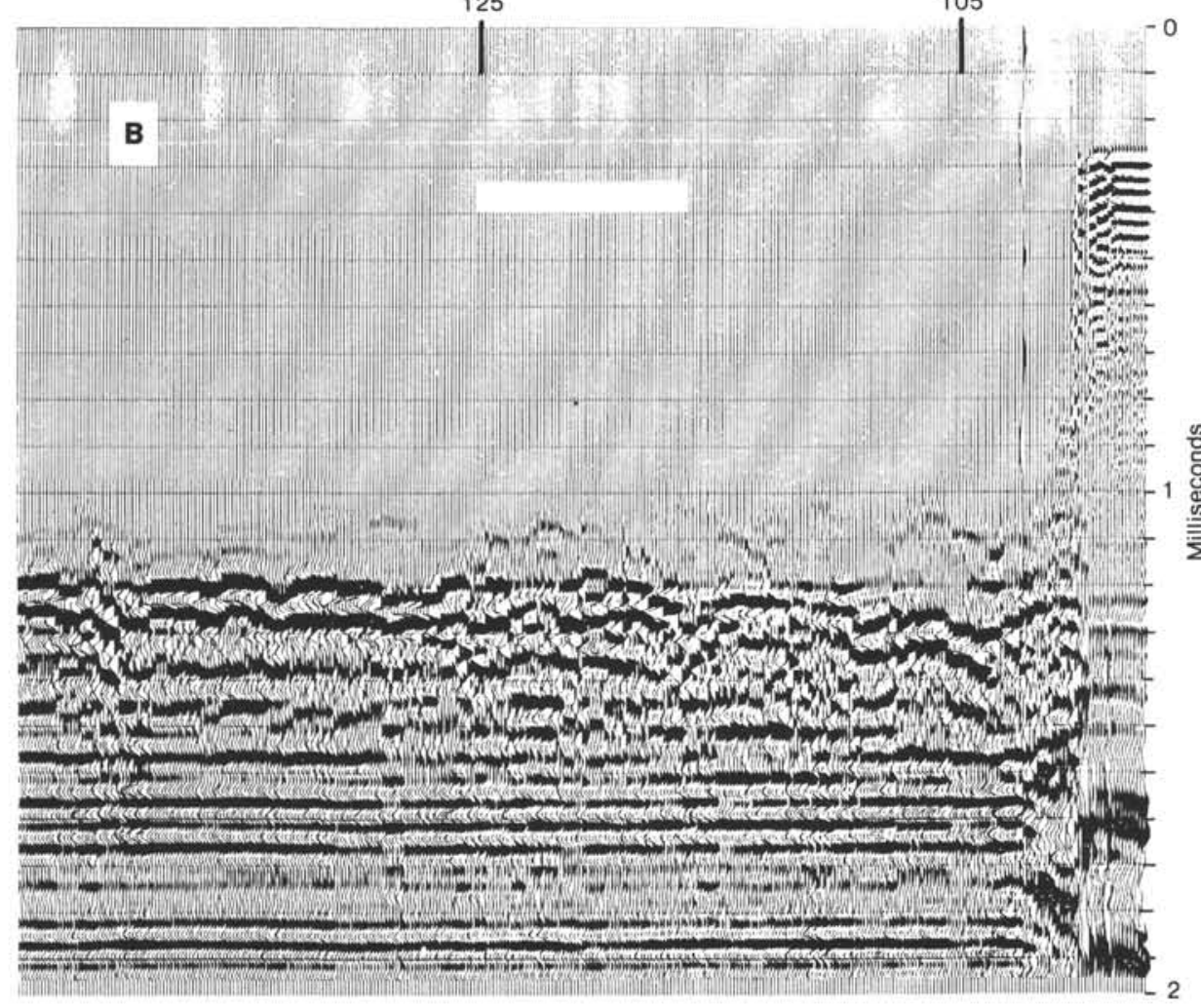

Figure 3. Instantaneous phase (A) and amplitude (B) display of long-space full-wave sonic data from Hole 583F. 


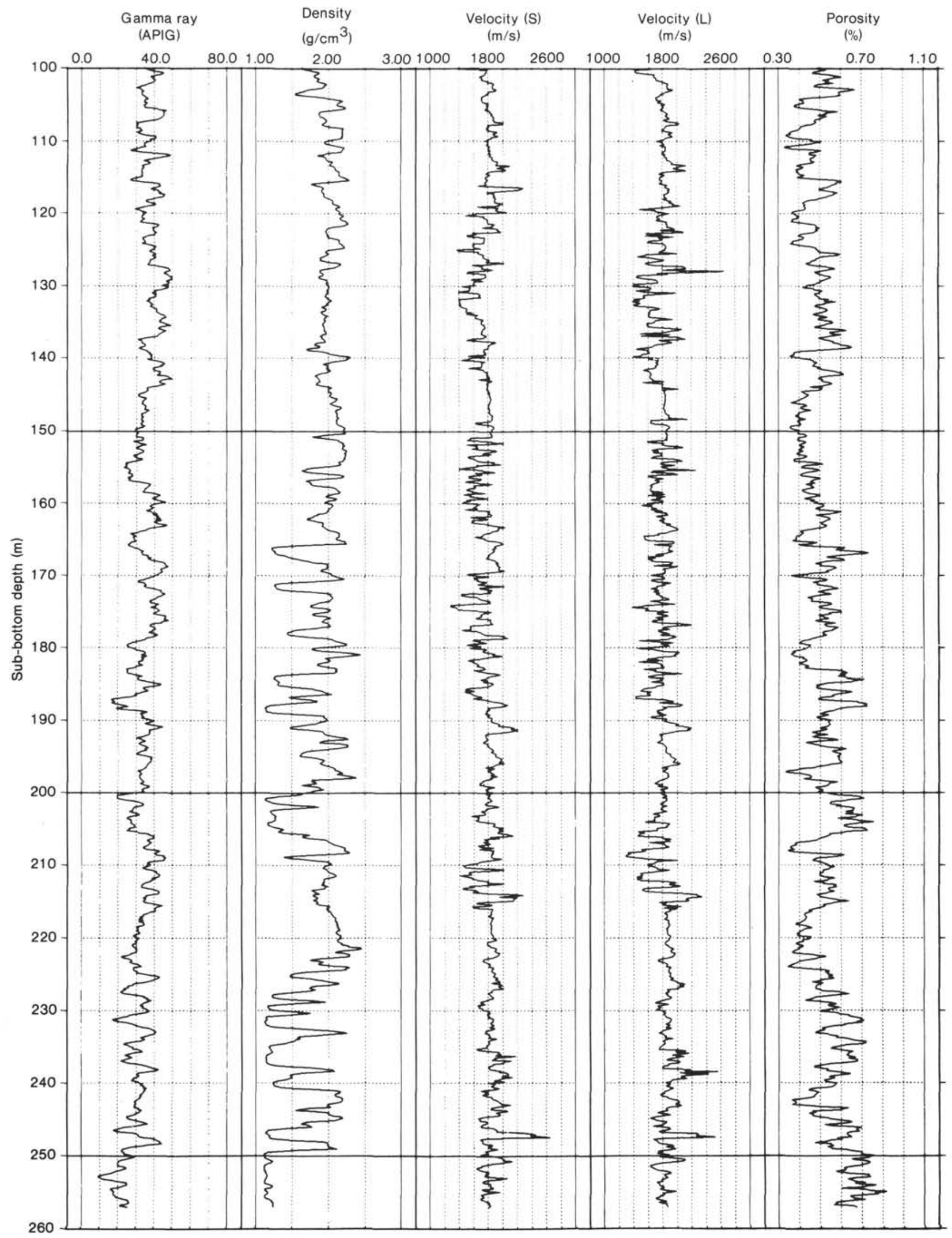

Figure 4. Logging data obtained from 100 to $257 \mathrm{~m}$ at Hole $583 \mathrm{~F}$. Velocity $(\mathrm{S})=$ short-space full-wave sonic velocity; Velocity $(\mathrm{L})=$ long-space full-wave sonic velocity. 


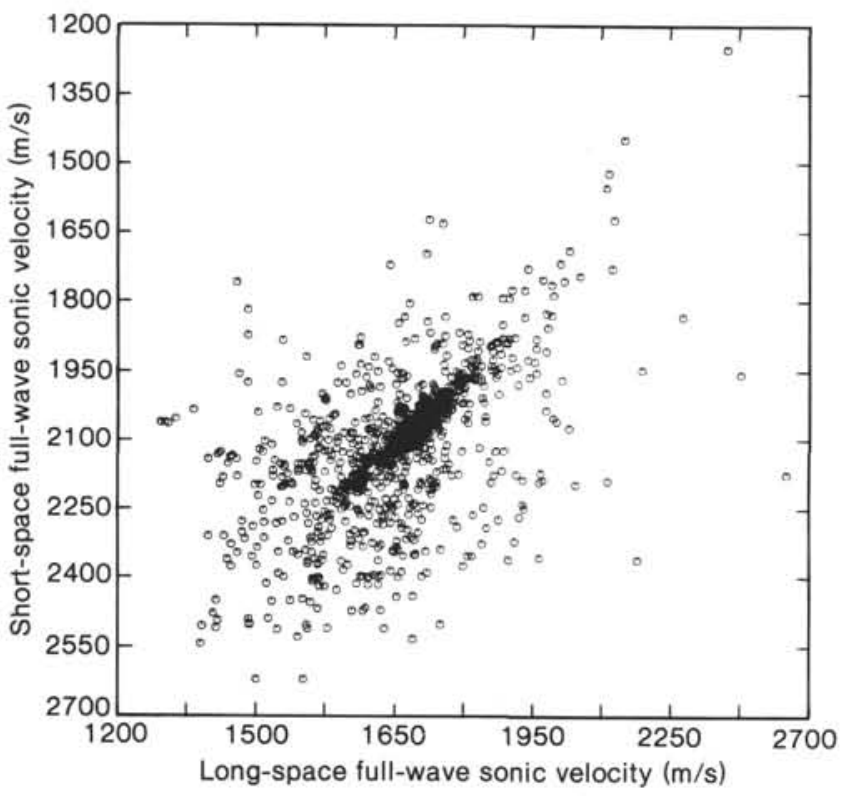

Figure 5. Crossplot of short-space and long-space full-wave sonic velocities, Hole 583F.

profile. Formation density also shows a well-defined inverse relationship with neutron porosity. Consequently, the velocity profile obtained in this study after calibration at Hole $583 \mathrm{~F}$ represents the velocity structure of this area. However, the migrated seismic section from which acoustic impedance is derived was not wavelet de- convolved, and the velocity structure shown here is generalized from that expected to occur naturally.

The velocity profile shown in this study strongly suggests a velocity decrease at the decollement below the accretionary toe. This zone, which consists mainly of pelagic sediment, is probably overpressurized. Similarly, the major thrust faults seen on the seismic profile may correspond to the passage of dehydrated water. During Leg 87, Hole 583 was drilled through Fault A (Fig. 2), but core samples from the fault were not recovered and this question remains unanswered by direct observation. According to the velocity structure obtained from seismic data, it is quite reasonable to consider the process in the following way. Once pelagic sediment or Shikoku Basin sediment is overlain by trench-wedge turbidites, the buried layer is overpressurized because interstitial water cannot be released through the sedimentary overburden. At this stage, the movement of the subducting ocean basement is transmitted to the trench-wedge turbidites by ductile flow of the pelagic sediment. A scaley claytype structure may be generated in the pelagic sediment but no apparent seismic scale deformation is observable, although trench-wedge turbidites show initial stages of deformation. A distinguishing feature at this stage is that no fault in the trench fill reaches the decollement.

In the next stage, the accretion of trench-wedge turbidites proceeds and the thickness of accreted sediment increases. As a result, the pore pressure of pelagic sediment may increase significantly. This effect, and generation of major faults such as Faults A and B (Fig. 2),

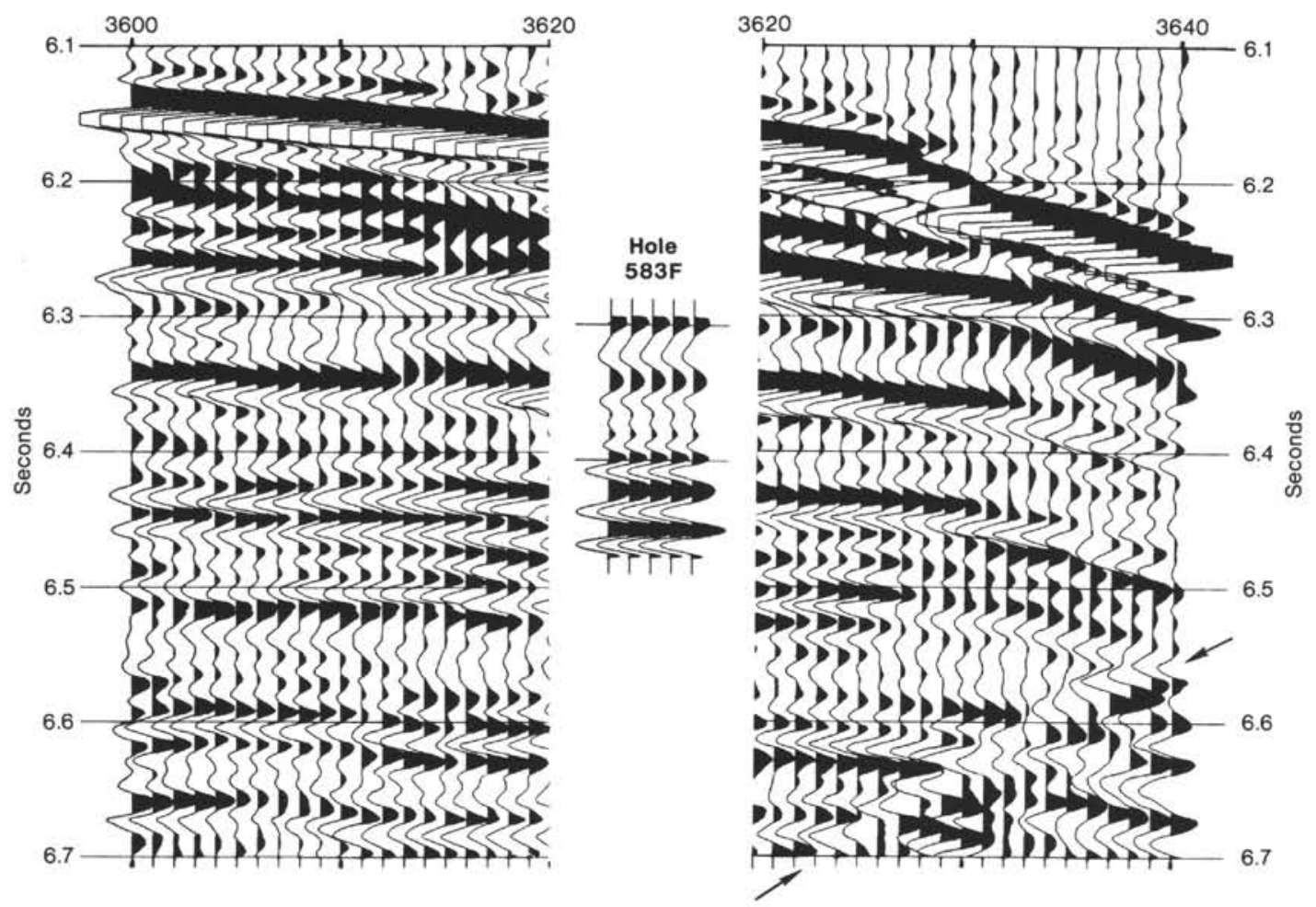

Figure 6. Correlation between the synthetic seismogram (center) and the seismic profile (normal polarity) (on left and right) that corresponds to the boxed-in section of Figure 2. Arrows indicate the major thrust Fault A in Figure 2. 


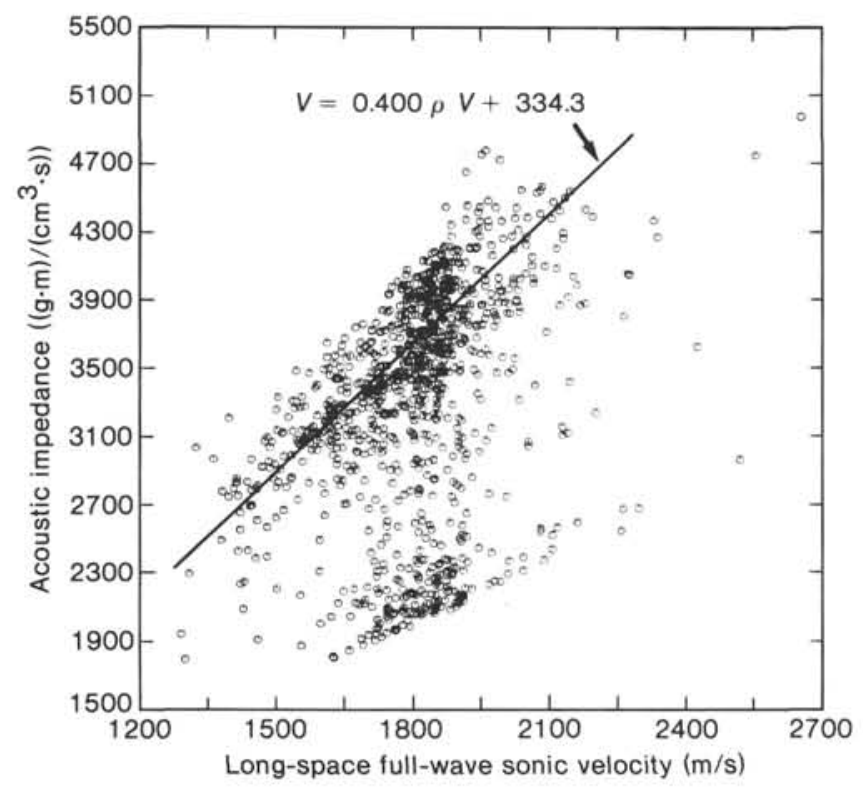

Figure 7. Crossplot display of long-space full-wave sonic velocity and acoustic impedance, Hole $583 \mathrm{~F}$. Solid line indicates a relationship between the two data if low acoustic impedance and low density data are discarded.

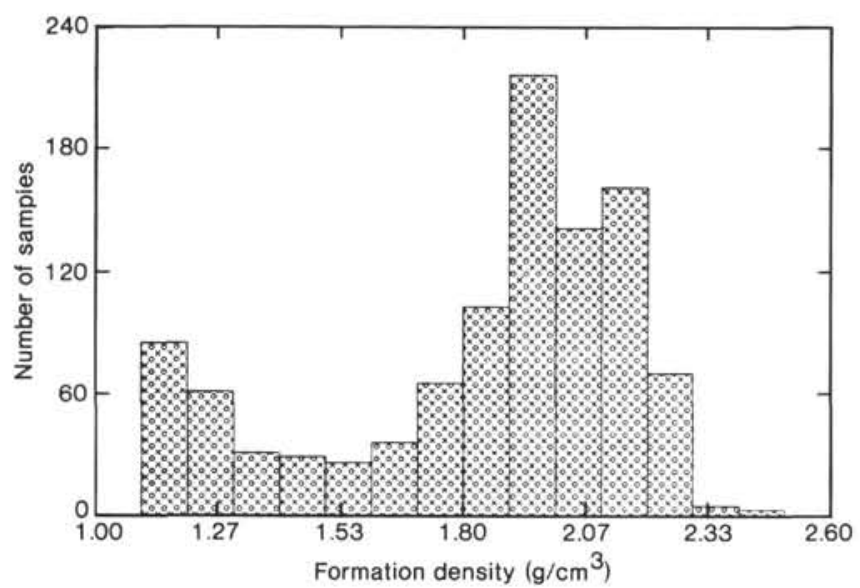

Figure 8. Histogram of formation density logged at Hole 583F.

enable the overpressurized pore water to escape to the seafloor. The characteristic features of Faults A and B (i.e., reflection from the fault plane and termination of the faults at the decollement) may be closely related to this process. As a consequence of pore water release, the

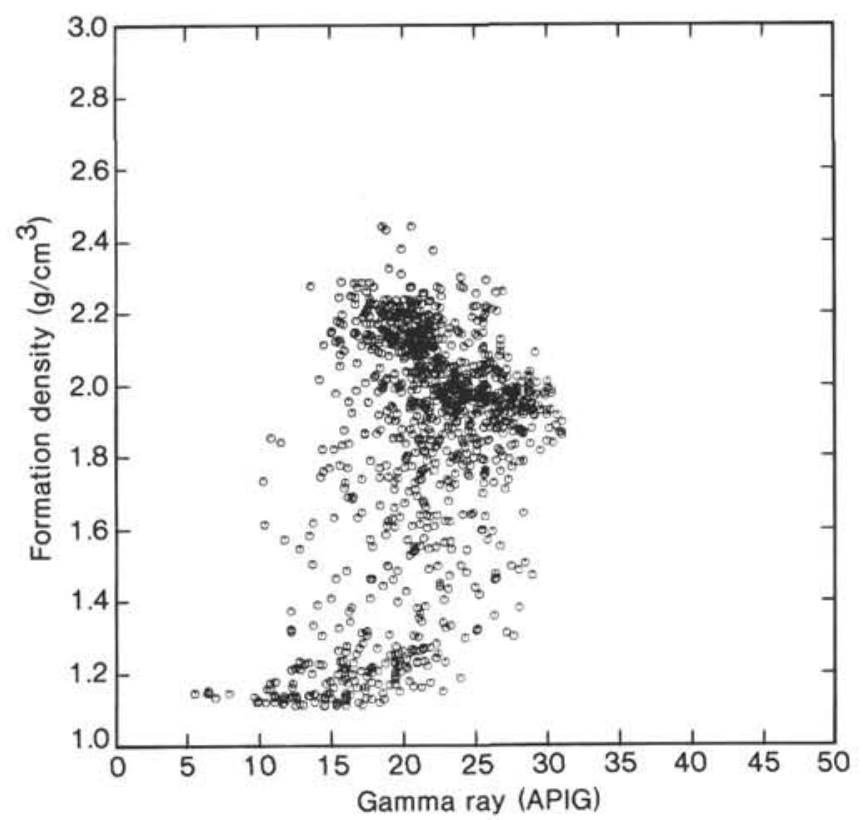

Figure 9. Relationship between gamma rays and formation density logged at Hole $583 \mathrm{~F}$.

seismic velocity of the pelagic layer tends to increase beyond the location of the major thrust faults. Significantly, the velocity increase of the pelagic layer occurs beneath the major thrust fault zone, suggesting that apparently stratified pelagic sediment beneath the accretionary toe would show brittle deformation at the more landward part of inner trench slope.

\section{ACKNOWLEDGMENT}

The authors wish to thank Japan Petroleum Exploration Co. for permitting the use of original seismic data for this study.

\section{REFERENCES}

Dix, C. H., 1955. Seismic velocities from surface measurements. Geophysics, 20:68-86.

Lavergne, M., and Willm, C., 1977. Inversion of seismograms and pseudo velocity logs. Geophys. Prospect., 25:232-250.

Lindseth, R. O., 1976. Seislog process uses seismic reflection traces. Oil Gas J., 74(43):67-71. 1979. Synthetic sonic logs-a process for stratigraphic interpretation. Geophysics, 44:3-26.

Nasu, N., et al., 1982. Multichannel Seismic Reflection Data Across Nankai Trough: Tokyo (Ocean Research Institute, University of Tokyo), IPOD-Japan Basic Data Series, No. 4.

Date of Initial Receipt: 3 July 1984

Date of Acceptance: 3 November 1984 


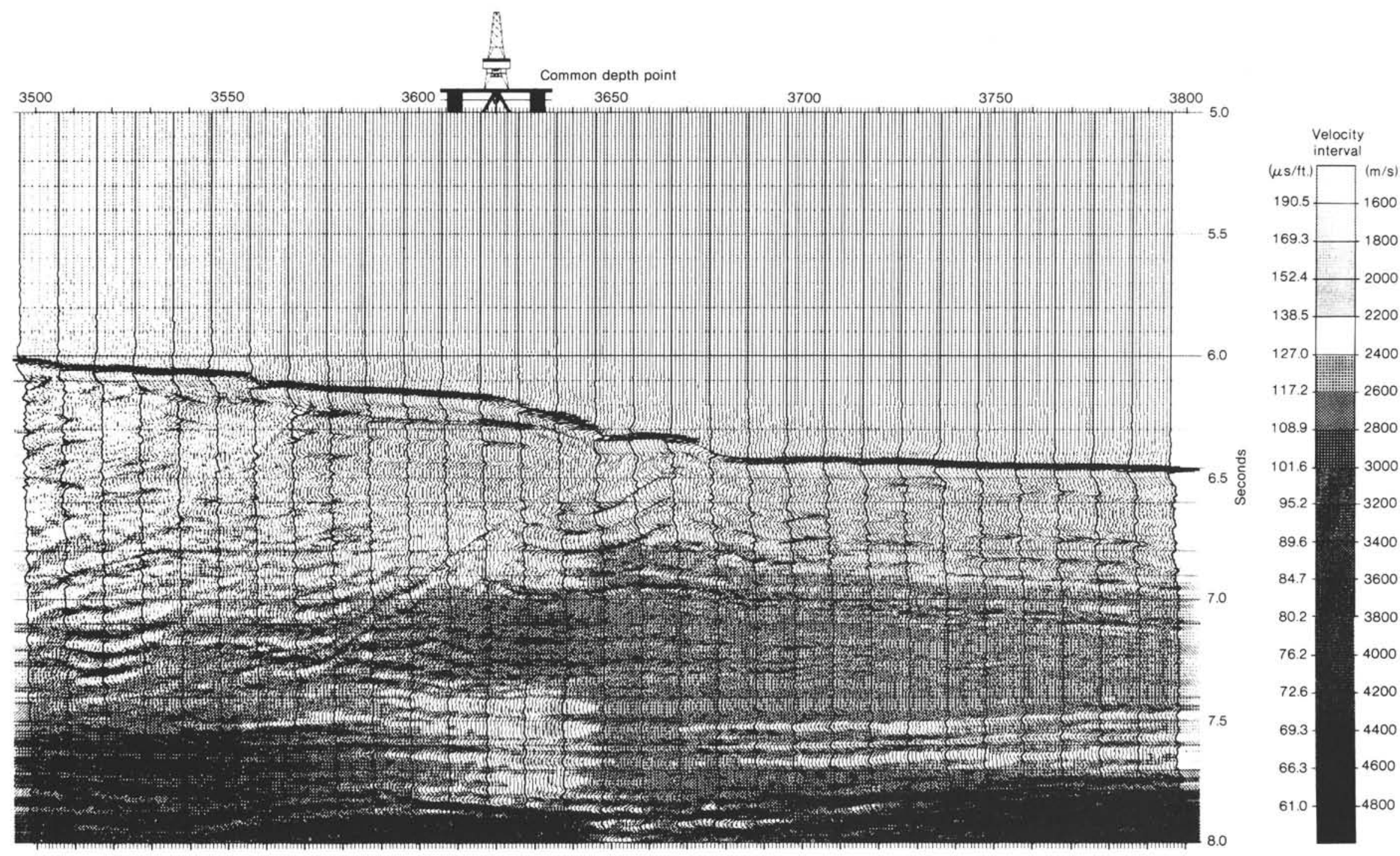

Figure 10. Velocity structure derived from the seismic profile of N55-3-1. Velocities are gray-scaled at every $200 \mathrm{~m} / \mathrm{s}$. The rig indicates the location of Hole $583 \mathrm{~F}$. (See frontispiece of this volume for color-coded version of this figure.) 